\title{
LOS MECANISMOS ALTERNATIVOS DE SOLUCIÓN DE CONTROVERSIAS COMO DERECHO HUMANO
}

\author{
THE ALTERNATIVE DISPUTE RESOLUTION MECHANISM AS A \\ HUMAN RIGHT
}

\author{
Egla Cornelio Landero \\ Universidad Juárez Autónoma de Tabasco, México/Mexico \\ liclandero@hotmail.com
}

Recibido/Received: 11/08/2014

Modificado/Modified: 18/08/2014

Aceptado/Accepted: 23/09/2014

\section{RESUMEN}

Los Derechos Humanos son los que posee la persona por el solo hecho de serlo, que todas las autoridades, en el ámbito de sus competencias, tienen la obligación de promover, respetar, proteger y garantizar, de conformidad con los principios de universalidad, interdependencia, indivisibilidad y progresividad. El Artículo 17 segundo párrafo de la Constitución Política de México contempla el derecho fundamental de acceso a la justicia como el derecho público subjetivo que toda persona tiene para que se le imparta justicia por tribunales expeditos, dentro de los plazos y términos previstos por las leyes, bajo principios de prontitud, justicia completa e imparcial. En el cuarto párrafo del mismo precepto constitucional a partir de junio de 2008 , se han reconocido como un derecho humano para acceder a la justicia los mecanismos alternativos de solución de controversias, que consisten en la negociación, mediación, conciliación y el arbitraje.

\section{PALABRAS CLAVE}

Justicia, mecanismos, gobernado, conflicto.

\section{SUMARIO}

1. El derecho humano de acceso a la justicia. 2. Acceso a la jurisdicción del Estado. 3. Acceso a los mecanismos alternativos de solución de controversias como un derecho humano. 4. Los mecanismos autocompositivos y los mecanismos heterocompositivos. 5. Conclusión. Bibliografía.

\begin{abstract}
Human rights are owned by the person for the simple fact of being, that all authorities within the scope of its powers, have the obligation to promote, respect, protect and ensure, in accordance with the principles of universality, interdependence, indivisibility and escalation. Second paragraph of Article 17 of the Constitution of Mexico, provides the fundamental right of access to justice and the public right that everyone has to be given to it for speedy justice courts, within the time and manner prescribed laws under principles of promptness, full and impartial justice. In the fourth paragraph of this constitutional provision since June 2008, has been recognized as a human right to access to justice, alternative dispute resolution mechanisms, which consist of negotiation, mediation, conciliation and arbitration.
\end{abstract}

\section{KEYWORDS}

Justice mechanisms, governed, conflict. 


\section{CONTENTS}

1. The human right of access to justice. 2. Access to the jurisdiction of the state. 3. Access to alternative dispute settlement mechanisms as a human right. 4 . The autocompositive mechanisms and heterocompositive mechanisms. 5. Conclusion. References

\section{EL DERECHO HUMANO DE ACCESO A LA JUSTICIA}

El acceso a la justicia es un Derecho Humano subjetivo que garantiza a la persona el puente para encontrar forma de solucionar sus dificultades cotidianas en las que se requiere el orden y participación del Estado, los derechos humanos son aquéllos que el hombre posee por el mero hecho de serlo (considerado individual y colectivamente), que emanan de los atributos de las personas, y que las normas jurídicas les otorga facultades, prerrogativas, libertades y pretensiones de carácter civil, político, económico, social y cultural. Son inherentes a la persona, inalienables, imprescriptibles, iguales, fuera del alcance de cualquier poder político. Son una constante histórica y de la defensa que se hace de la persona y su dignidad. Buscan el orden público, el bien común, el desarrollo y la democracia.

La prohibición de autotutela prevista en el primer párrafo del artículo 17 de la Constitución Política de los Estados Unidos Mexicanos, es el mandamiento público para que a toda reclamación de derecho recaiga una acción pacífica, que en todo Estado democrático, garantiza el acceso a los espacios de impartición y administración de justicia.

Es así, que como en toda aspiración de la persona a vivir en paz y concordia, es también la aspiración de tener un espacio a dónde acudir para reclamar un derecho cuando se siente lesionado y esperar en confianza que ha de ser escuchado y obtendrá una respuesta a su satisfacción. El Estado ha proscrito ejercer violencia para reclamar su derecho, por tanto debe ser garante de que exista amplia posibilidad de acceso para que tribunales imparciales impartan esa justicia, como dispone el Artículo 17 de la Constitución Política de los Estados Unidos Mexicanos:

Ninguna persona podrá hacerse justicia por sí misma, ni ejercer violencia para reclamar su derecho.

Toda persona tiene derecho a que se le administre justicia por tribunales que estarán expeditos para impartirla en los plazos y términos que fijen las leyes, emitiendo su resolución de manera pronta, completa imparcial.

En el texto constitucional está la disposición al gobernado de la vía o jurisdicción para reclamar el derecho de manera pacífica, con firme compromiso de impartir una justicia pronta, completa, expedita y gratuita, es lo deseable y debe ser lo real, como derecho humano. El proceso, es el medio civilizado para que con la intervención del Estado, el gobernado alcance la restitución de su derecho, se considera la vía oportuna para que el Estado le responda al gobernado a su necesidad de justicia, dictando el derecho para quien le asista y sancionando la conducta o acción de quien no le asista el derecho.

La justicia pronta, es la que el Estado debe dictar al gobernado o persona dentro de corto tiempo que no la haga tardía por falta de capacidad económica, por carecer de jueces capacitados o por saturación de tribunales carencia de espacios para dirimir las controversias.

Justicia completa, que los jueces y tribunales resuelvan lo que el justiciable ha pedido conforme a sus acciones y pretensiones, que no se resuelva a medias lo pedido, y le tengan que dar la justicia después de sendos recursos, tampoco basta que inicie un proceso, sino que lo desahogue y la sentencia sea cumplida. 
Justicia expedita, es la que el juez o los tribunales imparten despejada de todo obstáculo burocrático, sin contratiempos en los términos y plazos previstos por la ley, sin que las partes tengan que estar incitando a que se eviten procedimientos no apropiados a la vía o acción ejercida.

El acceso a la justicia es un derecho fundamental para que éste realmente se concrete en la esfera jurídica de los gobernados, es necesario precisar que se manifiesta en dos aspectos complementarios: uno formal y otro material. El aspecto formal del acceso a la justicia se refiere a la obligación de las autoridades de dar respuesta de manera pronta, completa, imparcial y gratuita a las solicitudes de los particulares (partes en un procedimiento) respetando las formalidades del procedimiento; desde luego que ello no significa que necesariamente se resolverá en forma favorable a los intereses del justiciable, sino sólo en los casos que en derecho proceda. Por su parte, el aspecto material del derecho de acceso a la justicia, complementa al primero, pues se refiere a la obligación de la autoridad de hacer cumplir sus resoluciones y, especialmente, cuando se trata de una sentencia definitiva o laudo que ha sido favorable a los intereses de alguna de las partes. Estas reflexiones parten de la tesis de Tribunales federales al estudiar el tema de este derecho humano, como lo ha publicado el Poder Judicial de la Federación en el Semanario Judicial de la Federación y su Gaceta, Tomo XXXIII, mayo de 2011, tesis XXXI.4K. Pág. 1105. ("Derecho de acceso a la justicia previsto en el artículo 17 de la Constitución Federal. Se respeta en la medida en que se atiende los aspectos formal y material en que se manifiesta", 2011)

\section{ACCESO A LA JURISDICCIÓN DEL ESTADO}

El derecho a la tutela jurisdiccional comprende el medio por el cual toda persona como integrante de una sociedad, puede acceder a los órganos jurisdiccionales previamente establecidos para ejercitar un derecho o defensas de sus intereses, con la confianza de que sea atendida a través de procesos que le ofrezca las garantías mínimas para su efectiva realización.

El derecho a la tutela jurisdiccional efectiva la Constitución Federal de México lo refiere en el segundo párrafo del artículo 17, como antes se ha mencionado que toda persona tiene derecho a que se le administre justicia por tribunales que estarán expeditos para impartirla, en concordancia con los diversos 14 que refiere a las formalidades esenciales del procedimiento y 20 apartados $\mathrm{B}$, de los derechos de toda persona imputada y $\mathrm{C}$, de los derechos de la víctima o del ofendido, los cuales refieren a similares garantías previstas en el artículo 8 de la Convención Americana sobre Derechos Humanos, que en su numeral 1 dispone: Toda persona tiene derecho a ser oída, con las debidas garantías y dentro de un plazo razonable, por un juez o tribunal competente, independiente e imparcial, establecido con anterioridad por la ley, en la sustanciación de cualquier acusación penal formulada contra ella, o para la determinación de sus derechos y obligaciones de orden civil, laboral, fiscal o de cualquier otro carácter.

En interpretación de la Suprema Corte de Justicia de la Nación este derecho puede comprender tres etapas ("Derecho de acceso a la justicia. Sus etapas", 2013), en las que se encuentra implícitos tres derechos: a) una previa al juicio, a la que le corresponde el derecho de acceso a la jurisdicción, que parte del derecho de acción como una especie del de petición dirigido a las autoridades jurisdiccionales y que motiva un pronunciamiento por su parte; $b$ ) una judicial, que va desde el inicio del procedimiento hasta la última actuación y a la que 
corresponden las garantías del debido proceso; y, c) una posterior al juicio, identificada con la eficacia de las resoluciones emitidas.

Pérez (1995) ha señalado que: El derecho a la tutela jurisdiccional despliega sus efectos en tres momentos distintos: primero, en el acceso a la justicia, segundo, una vez en ella, que sea posible la defensa y poder obtener solución en un plazo razonable, y tercero, una vez dictada la sentencia, la plena efectividad de sus pronunciamientos. Acceso a la jurisdicción, proceso debido y eficacia de la sentencia.

Para la Conferencia de Ministros de Justicia de los Países Iberoamericanos, COMJIB, el acceso a la justicia, es un derecho fundamental, bajo la garantía de igualdad de trato ante la ley y la no discriminación. Que posibilita a todas las personas, incluyendo aquéllas más vulnerables, el acceso al conocimiento ejercicio y defensa y obligaciones, mediante servicios cercanos, recuperado de (COMJIB, 2014).

Al respecto la Primera Sala de la Suprema Corte de Justicia de la Nación ha sostenido que el:

"Derecho de acceso a la justicia. Sus etapas". De los artículos 14, 17 y 20, apartados B y $\mathrm{C}$, de la Constitución Política de los Estados Unidos Mexicanos y 8 de la Convención Americana sobre Derechos Humanos, deriva el derecho de acceso efectivo a la justicia, el cual comprende, en adición a determinados factores socioeconómicos y políticos, el derecho a una tutela jurisdiccional efectiva y los mecanismos de tutela no jurisdiccional que también deben ser efectivos y estar fundamentados constitucional y legalmente. Ahora bien, como se señaló en la jurisprudencia 1a./J. 42/2007, de rubro: "Garantía a la tutela jurisdiccional prevista en el artículo 17 de la constitución política de los estados unidos mexicanos".

"Sus alcances", esta Primera Sala de la Suprema Corte de Justicia de la Nación definió el acceso a la tutela jurisdiccional como el derecho público subjetivo que toda persona tiene, dentro de los plazos y términos que fijen las leyes, para acceder de manera expedita a tribunales independientes e imparciales, a plantear una pretensión o a defenderse de ella, con el fin de que, a través de un proceso en el que se respeten ciertas formalidades, se decida sobre la pretensión o la defensa y, en su caso, se ejecute esa decisión; de ahí que este derecho comprenda tres etapas, a las que corresponden tres derechos: (i) una previa al juicio, a la que le corresponde el derecho de acceso a la jurisdicción, que parte del derecho de acción como una especie del de petición dirigido a las autoridades jurisdiccionales y que motiva un pronunciamiento por su parte; (ii) una judicial, que va desde el inicio del procedimiento hasta la última actuación y a la que corresponden las garantías del debido proceso; y, (iii) una posterior al juicio, identificada con la eficacia de las resoluciones emitidas. Los derechos antes mencionados alcanzan no solamente a los procedimientos ventilados ante jueces y tribunales del Poder Judicial, sino también a todos aquellos seguidos ante autoridades que, al pronunciarse sobre la determinación de derechos y obligaciones, realicen funciones materialmente jurisdiccionales. ("Garantía a la tutela jurisdiccional prevista en el artículo 17 de la constitución política de los Estados Unidos Mexicanos. Sus alcances”, 2007)

De la anterior jurisprudencia se desprende la definición de la garantía a la tutela jurisdiccional que es: el derecho público subjetivo que toda persona tiene, dentro de los plazos y términos que fijen las leyes, para acceder de manera expedita a tribunales independientes e imparciales, a plantear una pretensión o a defenderse de ella, con el fin de que a través de un proceso en el que se respeten ciertas formalidades, se decida sobre la pretensión o la defensa y, en su caso, se ejecute esa decisión. En la definición citada el máximo tribunal de nuestro país ha resumido lo que ya contempla la Carta Magna en los artículos 14 y 17, respecto al derecho fundamental de acceso de la justicia y el debido proceso. 
Finalmente cabe destacar que este derecho fundamental para que sea garantizado por el Estado, debe estar despojado de todo obstáculo de la índole que sea, para que cumpla con el espíritu de un derecho protector de derecho humano.

\section{ACCESO A LOS MECANISMOS ALTERNATIVOS DE SOLUCIÓN DE CONTROVERSIAS, COMO DERECHO HUMANO}

De la interpretación armónica del artículo 17 constitucional párrafo cuarto que dispone: que las leyes preverán mecanismos alternativos de solución de controversias, en concordancia con el 8 de la Convención Americana sobre Derechos Humanos, que reglamenta las garantías judiciales y el 14 del Pacto Internacional de Derechos Civiles y Políticos, que considera el derecho de igualdad de todas las personas ante los tribunales y el derecho al debido proceso. A partir de la reforma hacia un nuevo sistema de justicia penal en junio de 2008, fueron reconocidos dentro del sistema de justicia los mecanismos alternativos de solución de controversias.

En ese contexto, a partir del reconocimiento de estos mecanismos como alternativos a la solución de controversias, son diversos los Estados de la república mexicana que han legislado en referencia a esos mecanismos, sobre todo porque en la exposición de motivos de la reforma, se dijo que era necesario la práctica de estos mecanismos para descongestionar el saturación que tienen los tribunales en cuanto a procesos. En esta reflexión hay que resaltar que la Constitución Federal en el citado artículo 17 cuarto párrafo, además de garantizar el acceso a los tribunales previamente establecidos, reconoce como un derecho humano la posibilidad de que los conflictos también se puedan resolver a través de los mecanismos alternativos de solución de controversias, siempre que se encuentren previstos por la ley.

Al respecto el Poder Judicial de la Federación a través de su Colegiado de Circuito ha hecho pronunciamiento que como criterio resulta interesante porque ya se ha ocupado de estudiar la práctica de los mecanismos alternativos de solución de controversias, en el que define que gozan de la misma dignidad que el acceso a la jurisdicción del Estado.

"Acceso a los mecanismos alternativos de solución de controversias, como derecho humano. Goza de la misma dignidad que el acceso a la jurisdicción del Estado". Los artículos 17, segundo párrafo, de la Constitución Política de los Estados Unidos Mexicanos, 8 de la Convención Americana sobre Derechos Humanos y 14 del Pacto Internacional de Derechos Civiles y Políticos, reconocen a favor de los gobernados el acceso efectivo a la jurisdicción del Estado, que será encomendada a tribunales que estarán expeditos para impartir justicia, emitiendo sus resoluciones de manera pronta, completa e imparcial; en ese sentido, la Constitución Federal en el citado artículo 17, cuarto párrafo, va más allá y además de garantizar el acceso a los tribunales previamente establecidos, reconoce, como derecho humano, la posibilidad de que los conflictos también se puedan resolver mediante los mecanismos alternativos de solución de controversias, siempre y cuando estén previstos por la ley. Ahora bien, en cuanto a los mecanismos alternativos de solución de controversias, se rescata la idea de que son las partes las dueñas de su propio problema (litigio) y, por tanto, ellas son quienes deben decidir la forma de resolverlo, por lo que pueden optar por un catálogo amplio de posibilidades, en las que el proceso es una más. Los medios alternativos consisten en diversos procedimientos mediante los cuales las personas puedan resolver sus controversias, sin necesidad de una intervención jurisdiccional, y consisten en la negociación (autocomposición), mediación, conciliación y el arbitraje (heterocomposición). En ese 
sentido, entre las consideraciones expresadas en la exposición de motivos de la reforma constitucional al mencionado artículo 17, de dieciocho de junio de dos mil ocho, se estableció que los mecanismos alternativos de solución de controversias "son una garantía de la población para el acceso a una justicia pronta y expedita ..., permitirán, en primer lugar, cambiar al paradigma de la justicia restaurativa, propiciarán una participación más activa de la población para encontrar otras formas de relacionarse entre sí, donde se privilegie la responsabilidad personal, el respeto al otro y la utilización de la negociación y la comunicación para el desarrollo colectivo"; ante tal contexto normativo, debe concluirse que tanto la tutela judicial como los mecanismos alternos de solución de controversias, se establecen en un mismo plano constitucional y con la misma dignidad y tienen como objeto, idéntica finalidad, que es, resolver los diferendos entre los sujetos que se encuentren bajo el imperio de la ley en el Estado Mexicano. ("Acceso a los mecanismos alternativos de solución de controversias, como derecho humano. Goza de la misma dignidad que el acceso a la jurisdicción del Estado”, 2013)

\section{LOS MECANISMOS AUTOCOMPOSITIVOS Y LOS MECANISMOS HETEROCOMPOSITIVOS}

Los mecanismos de solución de conflictos también son cauces extra-jurisdiccionales surgidos al margen del proceso y desarrollados algunas veces por órganos no vinculados al poder estatal y otras veces por las mismas instancias estatales, a través de un conjunto de prácticas y técnicas dirigidas a: a) posibilitar la solución de los conflictos al margen de los tribunales en beneficio de todas las partes implicadas; b) reducir el costo y la dilación con relación al proceso judicial; y c) prevenir los conflictos jurídicos que estarían probablemente destinados a ser llevados ante los tribunales, coadyuvando en la búsqueda de tutela judicial efectiva (justicia).

El origen de los modernos métodos alternativos se ubica claramente en los Estados Unidos de América desde 1970, seguido por Canadá y Australia. Sobresale en este inicio que en 1972 el Servicio de Relaciones de la Comunidad del Departamento de Justicia de los Estados Unidos, recurrió a la utilización de mediadores para asistir a las partes en conflictos civiles en la comunidad.

En los años 90 se institucionalizan estos métodos, cuando el Congreso de los Estados Unidos de América impuso a todas las cortes federales la implementación y uso de los procedimientos de resolución de conflictos. En 1991, el presidente Bush resolvió mediante la orden ejecutiva 12.278, dirigida a todos los consejeros de litigio federal, que bajo circunstancias apropiadas debían sugerir métodos ADR a las partes privadas y utilizarlos para resolver reclamos contra los Estados Unidos.

En la actualidad los países europeos están practicando estos métodos en la solución y resolución de conflictos. En España trece comunidades autónomas han venido practicando la mediación y la negociación en los conflictos colectivos laborales. Recientemente, el 6 de julio de 2012, en España fue aprobada la Ley Estatal de Mediación en Asuntos Civiles y Mercantiles. Esto ocurre como seguimiento a la Carta Social Europea. Con estos métodos las partes se comprometen a fomentar el establecimiento y la utilización de procedimientos adecuados de conciliación y arbitraje voluntarios para la solución de conflictos laborales, por recomendación también del Parlamento Europeo. 
La autocomposición, afirma Carnelutti, es la composición del litigio que efectúan las partes referido por (Lara, 1990), unilateral o bilateral, y que pueden surgir durante el desarrollo de un juicio o fuera de él.

La costumbre y tradicionalismos de judicializar todos los conflictos, por pequeños o grandes, o por simples o complejos que fueran, fue agudizando la necesidad de pensar en otros métodos para resolverlos. Es así como hemos visto que día con día las partes acudían a métodos como el arbitraje tradicional, la negociación, la conciliación y la mediación. Pero éstos han tenido diferentes aplicaciones, sobre todo dentro del derecho. Sin embargo, refiere (Munguía, 1999), la manera "desordenada" como hasta ahora han sido utilizados, explica la confusión que existe sobre el significado y la peculiaridad de cada una de ellos. Además, que la participación del Estado ha sido incipiente en promocionar estos métodos para solucionar los conflictos.

Sin duda el propósito de la constitución y perfeccionamiento de las técnicas de resolución de conflictos es que al aplicarse de manera sistemática, las personas perciban las posibilidades que cada uno les puede ofrecer como mecanismos diferentes para encontrar soluciones a sus diferencias, al posibilitarles formas de comunicarse, componer las relaciones, gestionar el conflicto y en su caso resolverlo.

Las metas comunes de los mecanismos alternativos de solución de conflictos son: el mejoramiento del tejido social mediante relaciones de tolerancia, con apertura de canales para la participación de las minorías en un ambiente de verdadera democracia. También la generación de procesos que transformen conductas belicosas o violentas de la tradicional pedagogía del resentimiento y malestar en otras conductas pacíficas y de respeto por los derechos humanos.

Igualmente, es característico de estos métodos que las partes identifican la atribución del enfrentamiento esbozando soluciones; convirtiéndose en reguladoras de sus conflictos; generando reflexiones y espacios de convivencia para la paz; consolidando principios relacionales con criterios de equidad, tolerancia, respeto y una oportunidad invaluable: la vuelta al cumplimiento espontáneo de sus obligaciones, deberes, y responsabilidades en vez de mantenerse en la posición tradicional de buscar al culpable.

Un rasgo característico observado en el estudio que se ha venido haciendo de estos mecanismos alternativos de solución de conflictos, es que otorgan a las partes involucradas cierto protagonismo y una participación que el procedimiento judicial no les ofrece. Esto obedece a que las reglas son flexibles y no preestablecidas por procedimientos rigurosos, las partes son gestoras del avance del procedimiento de solución del conflicto, de manera que ellos se hacen dueños del tiempo y la forma como lo quieren solucionar.

En esa filosofía de estudio de los mecanismos alternativos de solución de conflictos, hemos encontrado diversas representaciones ejemplificadas de las características de cada uno de ellos. Sin embargo, en nuestra opinión estimamos pertinente recurrir al esquema gráfico número 1, denominado "Características de los mecanismos alternativos de solución de conflictos", a través del cual Manzur (2003) representa cada uno de los métodos.

Más allá de las características, simboliza el aspecto clave que tiene la función de cada uno, permitiendo ir de menor a mayor flexibilidad. Consecuentemente, podemos apreciar cuál es la participación del tercero en cada proceso para que las partes puedan con las metodologías diseñadas transitar en un proceso participativo encontrar soluciones a sus conflictos. 


\section{Gráfico 1}

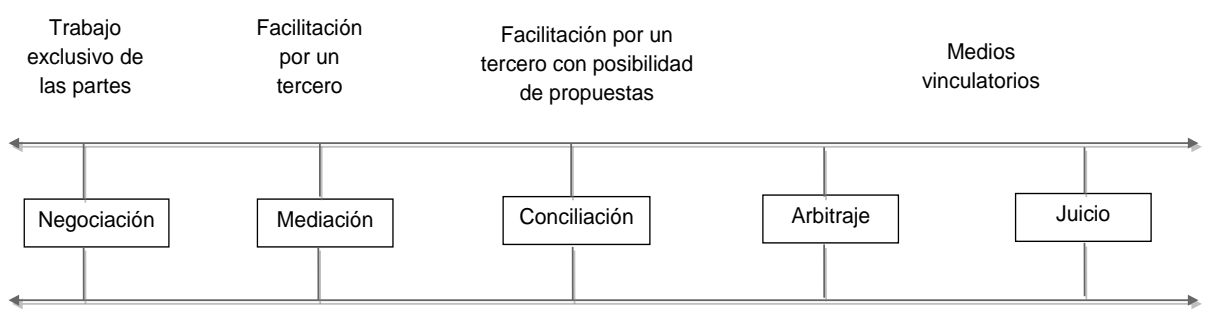

Mayor flexibilidad

Menor flexibilidad

Fuente: Manzur, C. A. (2003). Breviarios Jurídicos.

La Carta de Naciones Unidas en su Capítulo VI, refiere al arreglo pacífico de controversias, en el artículo 33 cuando las partes en una controversia lo requieran para mantener la paz y la seguridad internacional que se practiquen la negociación, la investigación, la mediación, la conciliación, el arbitraje, etc.

En el contexto expresado, se hace referencia a cada uno de los mecanismos de solución de controversias o de solución de conflictos de manera sucinta.

- Negociación

Abordar el tema de la negociación, es pensar y repensar en la preparación sólida y hábil que debe tener el mediador. Este es el mecanismo o técnica más usado, porque es parte de las relaciones tanto personales como de negocios diarios. En la familia negociamos, en nuestro trabajo negociamos, en los actos de comercio negociamos, en la política se negocia. De modo que la negociación consiste en que las partes se reúnen, solas o con la asistencia de sus abogados, pero sin la participación de un tercero y buscan resolver por sí mismas el o los asuntos que suscitaron el conflicto, dialogando e intentando convencer y persuadir a la otra parte para llegar a algún acuerdo.

Un concepto que (Calcaterra, 2002) nos aporta de la negociación es el de concebirlo como un proceso de comunicación directo o indirecto entre las partes, según la existencia o no de representantes, es decir, si aquéllas negocian cara a cara o a través de otras personas debidamente autorizadas por ellas.

Carrasco (2009) dice que negociación es la actividad distinta a obtener el acercamiento de posiciones entre diversas partes enfrentadas. Desde el punto de vista de la autora citada, la negociación es una técnica que puede ser utilizada por los terceros y las partes enfrentadas a la hora de conseguir la solución al conflicto.

Alfredo Islas Colín (2011) señala que, la negociación es una confrontación entre dos personas o grupos que comparten más o menos un proyecto común.

Negociar, dice Juan Maralet (2003), es un proceso de interacción potencialmente beneficioso, por el que dos o más persona con algún conflicto potencial o no, buscan mejorar sus opciones de negociación a través de acciones decididas conjuntamente.

El criterio para enfocar la negociación son los intereses y no las posiciones. De esta técnica destacamos, que las partes acuden con la mejor intención de negociar y tomar acuerdos satisfactorios a través de negociaciones directas o indirectas con la participación de un tercero. Sin embargo, la crítica más interesante que ha recibido esta técnica es que no 
toma suficientemente en cuenta que las partes no siempre son igualmente poderosas y que la diferencia de poder puede crear una desigualdad grave que genere un acuerdo injusto.

De acuerdo al modelo Harvard identifica tres tipos de negociadores, los negociadores duros, cuyo objeto es la victoria a cualquier precio, el negociador suave, su objetivo es la negociación amistosa y el negociador por principios, su objetivo es el acuerdo, separa a las personas del problema se centra intereses no en posiciones, genera alternativas buenas para ambas partes y está atento a posibles reclamaciones de valores.

Conforme a este modelo de Harvard las características de los buenos negociadores son: el que piensa rápido y claro, el que se expresa bien y con facilidad, el que tiene capacidad de análisis y de síntesis, es impersonal, es paciente, es capaz de considerar objetivamente las ideas de las otras personas, tacto, mantener su compostura y autocontrol, y buen humor.

- Arbritraje

El arbitraje es un mecanismo de los más antiguos incorporados al orden jurídico de muchos países en asuntos labores, mercantiles, comerciales, por citar algunos. El arbitraje es parecido al litigio en el sentido de que una tercera persona neutral, el árbitro, resuelve el conflicto de las partes después de haber considerado los hechos y argumentos presentados por las partes y sus abogados. Sin embargo, el árbitro es una persona privada, no un juez. Lo más frecuente es que las partes acudan al arbitraje voluntariamente y en algunos casos pueden decidir sobre ciertos aspectos del procedimiento Tesis: I.3o.C.934 C, Semanario Judicial de la Federación y su Gaceta, Novena Época, Tribunales Colegiados de Circuito, XXXIII, Mayo de 2011, P. 1018. El árbitro tiene como función escuchar lo que cada parte desee exponer para defender su punto de vista $\mathrm{y}$, con base en ello, tomar una decisión vinculante.

Algunos autores como Manzur (2003) conceptualizan el arbitraje como el medio que ha dado lugar a un mayor número de corrientes en torno a su naturaleza jurídica. Su estudio ha transcurrido el extremo de considerarlo un proceso de carácter jurisdiccional, debido a la similitud que existe entre la actividad del árbitro y la del juez, e incluso al extremo de calificarlo como un contrato; que el arbitraje es un procedimiento de solución de controversias de carácter privado previsto en la ley.

Para Carrasco (2009), el arbitraje se puede definir como una institución a través de la cual las personas naturales o jurídicas someten mediante una declaración de voluntad las cuestiones litigiosas actuales o futuras que surjan en una materia de libre disposición a la decisión de uno o varios árbitros, vinculándolos a dicha resolución.

Dentro de los mecanismos alternativos de solución de conflictos el arbitraje es autocompositivo si se basa únicamente en la voluntad de las partes y en la contractualidad; y heterocompositivo cuando el árbitro, más que intervenir por voluntad de los contratantes, tiene una actuación determinada por la ley. Por ello, si el arbitraje se presenta por una decisión voluntaria, libre y concertada (como ocurre en los arbitrajes privados civiles o comerciales puros) sus fundamentos tendrán naturaleza meramente contractual, esto ha sido sostenido por la Primera Sala de la Suprema Corte de Justicia de la Nación Novena Época, Instancia: Primera Sala, Tipo de Tesis: Aislada, Fuente: Semanario Judicial de la Federación y su Gaceta, Localización: Tomo XXX, Septiembre de 2009, Materia(s): Civil, Tesis: 1a. CLXV/2009, pág.: 434.

El concepto de arbitraje los Tribunales Colegiados Tesis: I.3o.C.937 C, Semanario Judicial de la Federación y su Gaceta, Novena Época, Tribunales Colegiados de Circuito, XXXIII, Mayo de 2011, P. 1017. lo han expresado al resolver la litis que se planteó al interpretar el Artículo II.1 de y al efecto sostuvo que: La Convención sobre el 
Reconocimiento y Ejecución de las Sentencias Arbitrales Extranjeras, publicada en el Diario Oficial de la Federación el veintidós de junio de mil novecientos setenta y uno, en su Artículo II. 1, define al arbitraje como el acuerdo por escrito conforme al cual las partes se obligan a someter a arbitraje todas las diferencias o ciertas diferencias que hayan surgido o puedan surgir entre ellas respecto a una determinada relación jurídica, contractual o no contractual, concerniente a un asunto que pueda ser resuelto por arbitraje.

El arbitraje es un mecanismo alternativo trilateral en donde el tercero tiene poder de vincular a las partes con una decisión definitiva. Se trata de un procedimiento de solución de conflictos donde las partes, por medio de un acuerdo de voluntades, expresan su deseo de someter una controversia $u$ otras situaciones que puedan surgir de la decisión de un tercero llamado árbitro.

La fracción I del Artículo 1416 del Código de Comercio dispone que el acuerdo de arbitraje es aquel por el que las partes deciden someter a arbitraje todo o ciertas controversias de una determinada relación jurídica, contractual o no contractual, la cual podrá adoptar la forma de una cláusula compromisoria o la forma de contrato independiente. Esta disposición legal confirma que el arbitraje tiene su origen en el acuerdo de las partes que, por un lado, determina qué cuestiones deben resolverse mediante esa institución y, por otro, la previsión de un procedimiento como el medio necesario para decidir la controversia Tesis: I.3o.C.936 C, Semanario Judicial de la Federación y su Gaceta, Novena Época, XXXIII, Mayo de 2011, P. 1008.

En todo arbitraje subyace el hecho de que existe una controversia originada por una relación jurídica que puede ser contractual o extracontractual.

La actitud del árbitro estriba en que él decide la controversia conforme a disposiciones jurídicas determinadas por las partes. El resultado de un arbitraje tiene un efecto jurídico a través de una resolución: es un laudo definitivo con fuerza vinculatoria para las partes. El Artículo 1423 del Código de Comercio establece que, por regla general, el acuerdo debe constar por escrito y consignarse en un documento firmado por las partes; pero también prevé la aplicación del principio de equivalencia funcional, cuando la voluntad de las partes se puede apreciar en documentos que no sea expresamente el contrato, Tesis: I.3o.C.938 C, Semanario Judicial de la Federación y su Gaceta, Novena Época, Tribunales Colegiados de Circuito, XXXIII, Mayo de 2011, P. 1018.

Se puede distinguir varios tipos de arbitraje en función de múltiples criterios: Según su administración nos podemos encontrar con el arbitraje ad hoc o el arbitraje institucional. En el primero, libre o independiente, son las propias partes quienes regulan el arbitraje estableciendo ellas mismas las normas del procedimiento de los árbitros. En el segundo, las partes se dirigen a una institución especializada, que será quien administrará el arbitraje según lo establecido en su reglamento.

Según la forma de acceso, en este sistema hay arbitraje voluntario y arbitraje forzoso. El primero de ellos, es el que se produce como consecuencia de la voluntad de las partes; el arbitraje forzoso determina la sujeción del caso a arbitraje por disposición legal.

Ahora, según su modalidad, se encuentran el arbitraje de derecho y el arbitraje de equidad. En el arbitraje de derecho los árbitros juzgan el supuesto adecuando el laudo al Derecho sustantivo, mientras que en el arbitraje de equidad los árbitros pueden obrar según su leal saber y entender.

Es posible que en algunas ocasiones encontremos criterios de arbitraje. Según el ámbito territorial, se distingue entre el arbitraje nacional y el internacional. El primero, es aquel procedimiento que resuelve conflictos entre partes establecidas en el mimo territorio, 
mientras que el arbitraje internacional se caracteriza porque las partes que celebran el convenio arbitral tienen domicilio en Estados diferentes.

Una diferencia sustancial entre el arbitraje y la decisión judicial es que el árbitro a diferencia del juez, no decide quién es culpable, sino que se limita a señalar cuál es en su opinión la solución más justa para poner fin al conflicto, resolución a la que por voluntad las partes se comprometen a respetar.

Se considera que esta técnica es similar a la de un proceso judicial porque en ambos casos, es una tercera persona la que resuelve, tal como lo comenta Martínez de Munguía. Por eso, una característica que también podemos darle al arbitraje es la de ser un mecanismo heterocompositivo.

Las facultades del árbitro se derivan de la voluntad de las partes que sí, en efecto, debe estar expresada según lo dispuesto en la ley; sin embargo, las partes pueden acordarlo, diseñarlo, modificarlo en cierto momento, pero siempre con sujeción a lo dispuesto por la propia ley y dentro de sus límites, Tesis: I.3o.C.948 C, Semanario Judicial de la Federación y su Gaceta, Novena Época, Tribunales Colegiados de Circuito, XXXIII, Mayo de 2011, P. 1239.

Esto, porque como está previsto en el Código, solo pueden someterse al arbitraje las cuestiones que sean de libre disposición para las partes, como reflejo del principio proveniente del Artículo 1798 del Código Civil Federal, de aplicación supletoria al Código de Comercio, de manera que cuando la materia resuelta en el laudo correspondiente no es susceptible de arbitraje, se cae en la hipótesis de que sea cuestionado la licitud del objeto del convenio arbitral.

Por ello, el laudo únicamente afecta a las partes involucradas, no a terceros. No crea precedentes obligatorios porque sólo ellas han manifestado su deseo de someter determinadas o futuras controversias a dicho mecanismo.

Esto es por demás evidente cuando el Código de Comercio, por ejemplo, establece ese medio y fija procedimiento, Tesis: I.3o.C.935 C, Semanario Judicial de la Federación y su Gaceta, Novena Época, Tribunales Colegiados de Circuito, XXXIII, Mayo de 2011, P. 1019.

Sin olvidar que en México a partir de la celebración del Tratado de Libre Comercio, en el Artículo 1904 Publicado en el Diario Oficial de la Federación del 8 de diciembre de 1993, se contempla el procedimiento arbitral denominando Panel de Revisión de Resoluciones Definitivas sobre Antidumping y Cuota compensatorias de una Autoridad nacional, que si bien estas controversias hoy en día terminan resolviéndose en paneles, no podemos ignorar que hay la participación de árbitros.

Con el crecimiento del comercio internacional también ha existido el crecimiento de los conflictos de comercio internacional que terminan resolviéndose en arbitrajes internacionales, en los que cobra vigencia los tratados internacionales de arbitraje de los que nuestro país es parte. Podemos citar entre ellos: Convención de Naciones Unidas sobre el Reconocimiento y Ejecución de Sentencias Arbitrales Extranjeras de 1958, también conocida como "Convención de Nueva York" Publicada en el Diario Oficial de la Federación del 22 de junio de 1971. La Convención Interamericana Diario Oficial de la Federación del 27de abril de 1976, conocida también como "Convención de Panamá". La Convención Interamericana sobre Eficacia Extraterritorial de las Sentencias y Laudos Arbitrales Extranjeros Diario Oficial de la Federación del 28 de agosto de 1976, conocida como "Convención de Montevideo", y la Convención Bilateral en los Estados Unidos Mexicanos y el Reino de España sobre Reconocimiento y Ejecución de Sentencias Judiciales y Laudos Arbitrales Civiles y Mercantiles, Diario Oficial de la Federación del 5 de marzo de 1992. 


\section{- Conciliación}

Probablemente es uno de los mecanismos de solución de conflictos más practicado, porque algunas veces la encontraremos como institución procesal, otras como un medio para llegar acuerdos en controversias administrativas, o simplemente, es una vía que amigablemente construyen las partes cuando tienen el deseo de encontrar solución a alguna situación que les genera conflicto.

La conciliación es un proceso voluntario al que acuden dos o más personas que tienen un conflicto para que, con la ayuda de un tercero profesional (conciliador), quien participa de manera imparcial y neutral sugiriéndoles posibles alternativas de solución, construyan acuerdos para solucionar su conflicto, conforme lo escrito por Alfredo Islas Colín (2011).

Así, la conciliación es una institución procesal mixta que consiste exclusivamente en la actividad del magistrado que convoca al acto, enderezado a lograr la autocomposición del juicio, (Gaidrois, 1995), esto es, que la conducta desplegada por el juzgador o conciliador judicial puede lograr la transacción de un caso y que con el convenio de las partes se ponga fin a la contienda judicial.

Sin embargo, tampoco podemos perder de vista que la conciliación es un mecanismos consensual, estrictamente voluntario que sólo puede aplicarse cuando existe un consentimiento expresado por las partes involucradas, según Manzur (2003). Por eso también, tiene la característica de ser un mecanismo autocompositivo, porque las partes son partícipes de sus propios acuerdos.

Para augurar éxito a este tipo de conciliación, deben considerase aspectos como: asegurar siempre el carácter consensual y voluntario de este mecanismo; insistir en la habilidad e imparcialidad para avenir a las partes; la debida capacitación y profesionalización de los conciliadores, quienes deben ser ajenos a los que realizan actividades de asesores en las propias instituciones, así como informar adecuadamente a las partes para orientarlas a verdaderos acuerdos haciéndoles saber las ventajas y desventajas del mecanismo.

- Mediación

La mediación es un mecanismo alternativo de resolución de conflictos. Algunos la consideran como la técnica más novedosa y que promete mayores éxitos en el campo de la resolución de conflictos, porque deja en manos de las partes, asistidas por un tercero imparcial, la solución de su propia situación de conflicto. Según la interpretación más optimista, la mediación es una herramienta para la transformación de las relaciones sociales, de acuerdo a lo sostenido por Munguía (1999).

De la diversa información que surge de la doctrina, se advierte que la práctica de la mediación en todo el mundo ha tenido un inmenso crecimiento en las últimas tres décadas. La principal razón puede imputársele a su efectividad.

Antes de continuar abordando el tema de la mediación, consideramos pertinente asentar la definición gramatical de la palabra mediación (del lat. Mediatio, -ónis) acción y efecto de mediar, el significado de la palabra mediar (del lat. Mediáre) interceder o rogar por alguien. Interponerse entre dos o más que riñen o contienden, procurando reconciliarlos y unirlos en amistad. (Diccionario de la lengua española, Real Academia Española 2001).

De las definiciones expuestas por Folberg y Taylor, C. Moore, Salvador Puntes y S. Ferre, (2008) podemos decir que la mediación es un proceso de resolución o gestión de conflicto, en donde las partes asisten voluntariamente y con la ayuda de un tercero profesional, construyen acuerdos tomando decisiones de manera natural sobre el tema motivador del conflicto.

Una definición clásica en la que casi todos los autores consultados coinciden, dice que la mediación es la técnica mediante la cual son las partes mismas inmersas en un conflicto 
quienes tratan de llegar a un acuerdo con ayuda de un mediador, tercero imparcial, que no tiene facultades de decisión (Schiffrin, 2005).

Podríamos decir que la mediación es un proceso cuyo objetivo es identificar los puntos en conflicto e intentar, a través de técnicas específicas, que las partes lleguen a un acuerdo.

Algunos autores consideran que los términos conciliación y mediación son sinónimos. No obstante, son bastante distintos como técnica o procedimiento, como más adelante daremos a conocer al identificar sus características.

A diferencia del arbitraje, la conciliación y la mediación plantean menor problema, debido a la incapacidad del tercero de obligar a las partes con una resolución. El conciliador y el mediador sólo facilitan el diálogo, coadyuvan con las partes en la solución del conflicto; no imponen una solución. Son mecanismos consensuales, rigurosamente voluntarios, que sólo pueden aplicarse cuando existe una anuencia claramente expresada por las partes involucradas. El tercero neutral tiene únicamente una función facilitadora, no cuenta como el árbitro y como el juez con la facultad de decidir.

Ponerse de acuerdo es uno de los objetivos de la mediación, entendida ésta como un procedimiento voluntario, informal, confidencial e integrador, a través de la cual un tercero imparcial y neutral interviene para ayudar a las partes en conflicto a trabajar cooperativamente, intentando lograr un acuerdo mutuamente satisfactorio o al menos aceptable para ellos.

Por lo demás, lo único que se requiere es la voluntad de las partes y un profesional en la mediación, así como los espacios idóneos para practicar dicho proceso.

La imparcialidad del tercero debe ser congruente con las características a emplear en cada proceso; no tomar partido, ni en favor ni en contra de ninguna de las partes. Su comportamiento debe ser claro en el sentido de no favorecer a ninguna parte en detrimento de la otra y de reconocer los argumentos e intereses de cada una, así como la oportunidad de expresarlos.

El gran auge que ha venido teniendo este mecanismo de resolución de conflicto se debe a que los acuerdos son más duraderos. Posiblemente porque durante el trabajo de gestión del conflicto las partes no solamente trabajan al exterior de sus posiciones e intereses, sino también en la construcción interior de tolerancia y confianza de la propia persona.

Antes de estar previsto en la Carta Magna la obligación de que en todas las leyes se previeran mecanismos de solución de controversias, estos Estados legislaron sobre el tema de leyes de conciliación, mediación y en algunos casos el arbitraje, quedando legitimadas dichas legislaciones a partir de la reforma constitucional de junio de 2008.

En la actualidad son 29 Estados que han legislado sobre el tema, como son: Aguascalientes, Baja California, Campeche, Coahuila, Colima, Chiapas, Chihuahua, Distrito Federal, Durango, Guanajuato, Hidalgo, Jalisco, Estado de México, Morelos, Nayarit, Nuevo León, Oaxaca, Puebla, Querétaro, Quintana Roo, Sonora, Tabasco, Tamaulipas, Tlaxcala, Veracruz, Yucatán, Zacatecas, San Luis Potosí, Michoacán. El 4 de marzo de 2014, el titular del Poder Ejecutivo Federal, envió a la Cámara de Diputados la iniciativa de Ley Nacional de Mediación Penal, para complementar el Código Nacional de Procedimientos Penal, como lo prevén los artículos 17 y 18 constitucional. 


\section{CONCLUSIONES}

Primera. Siendo pues el acceso a la jurisdicción del Estado, un derecho humano, los mecanismos alternativos de solución de controversias como la negociación, mediación, arbitraje y conciliación, se encuentran también reconocidos como un derecho humano a la dignidad de acceso a la jurisdicción del Estado, y pueden ser practicados válidamente siempre que sean procedentes y se encuentren reconocidos por la legislación.

Los mecanismos alterativos de solución de conflictos cada vez están teniendo mayor uso, sobre todo, por las formas de practicarse como hemos venido comentando. Por su flexibilidad, permiten que las partes en conflicto vean resultados en menos tiempo, lo que no ocurre cuando estamos frente a un proceso preestablecido, como acontece en los juicios regulados por determinada norma jurídica procesal. En efecto, tener hoy reconocidos los medios alternos de solución de controversias en los Artículos 17 y 18 de la Carta Magna, no es más que poner al alcance de los gobernados otras formas legítimas para solucionar su conflicto.

Segunda. Los conflictos son situaciones que se presentan a las personas en todos los tipos de relaciones, de manera que en la relaciones laborales también se encuentran presentes con frecuencia, porque los centros de trabajos son espacios donde convergen diversidad de personas, con intereses, formaciones, culturas, costumbres y valores. Pero también, los conflictos son oportunidades para transformar relaciones, modificar conductas o visto de otra manera, son oportunidades de crecimiento.

En consecuencia, es de toral importancia que los conflictos sean abordados de manera adecuada y oportunamente, toda vez que, por el estado del tiempo los conflictos son emergentes, latentes y manifiestos. Si un conflicto se deja pasar y no se atiende a tiempo, la posible solución al mismo no tan solo puede ser compleja, sino también difícil.

Tercera. Los sistemas tradicionales de solución de conflictos, desde hace más de tres décadas se encuentran saturados debido a que han sido rebasados por las cargas de trabajo, por la falta de capacitación y posiblemente, porque los tribunales, juzgados y juntas de conciliación no tienen los espacios ni los instrumentos de trabajo suficientes para hacer frente a los cúmulos de juicios que tienen asignados.

Es así que se debe trabajar por dar a conocer estos mecanismos alternativos como son la conciliación, la negociación, la mediación y el arbitraje, porque es un derecho fundamental de acceso a la justicia que tienen los gobernados, por tanto tampoco deben seguir siendo monopolio del Estado, sino deben estar al alcance del gobernado, además, que éstos no tienen la finalidad de ser opuestos o contrarios a los mecanismos jurisdiccionales de solución de controversias, sino ser colaborativos e incluyentes en la búsqueda de cumplir con los sistemas de la efectiva justicia.

\section{BIBLIOGRAFÍA}

ACCESO A LOS MECANISMOS ALTERNATIVOS DE SOLUCIÓN DE CONTROVERSIAS, COMO DERECHO HUMANO. GOZA DE LA MISMA DIGNIDAD QUE EL ACCESO A LA JURISDICCIÓN DEL ESTADO, III.2o.C.6K (10a.) (México: Segundo Tribunal Colegiado en Materia Civil del Tercer Circuito, Octubre, Tomo 3 de 2013).

CALCATERRA, R. A. (2006). Mediación estratégica. Barcelona: Gedisa.

CARRASCO, M. B. (2009). Mediación y sistemas alternativos de resolución de conflictos, una visión jurídica. Madrid, España: Reus. 
COMJIB, C. D. (27 de mayo de 2014). http://www. comjib.org/acceso-a-la-justicia.

DERECHO DE ACCESO A LA JUSTICIA PREVISTO EN EL ARTÍCULO 17 DE LA CONSTITUCIÓN FEDERAL. SE RESPETA EN LA MEDIDA EN QUE SE ATIENDE LOS ASPECTOS FORMAL Y MATERIAL EN QUE SE MANIFIESTA, XXXI. 4K (México: Tribunal Colegiado del Trigésimo Primer Circuito, Mayo de 2011).

DERECHO DE ACCESO A LA JUSTICIA. SUS ETAPAS, 1a. LXXIV/2013(10a.) (Suprema Corte de Justicia de la Nación, Primera Sala, Marzo de 2013).

GAIDROIS, Z. D. (1995). Qué es la mediación. Argentina: Abeledo-perrot.

GARANTÍA A LA TUTELA JURISDICCIONAL PREVISTA EN EL ARTÍCULO 17 DE LA CONSTITUCIÓN POLÍTICA DDE LOS ESTADOS UNIDOS MEXICANOS. SUS ALCANCES, 1a./j.42/2007 (México: Suprema Corte de Justicia de la Nación, Primera Sala, Abril de 2007).

ISLAS COLÍN, I. (2011). Juicios orales en México, Tomo I. México, D.F.: Flores Editores. LARA, C. G. (1990). Teoría general del proceso. México, D.F.: Harla.

MARALET, J. P. (2003). Manual de negociación y mediación, negociaciones empresariales eficaces para juristas y directivos de empresas. Madrid: COLEX.

MANZUR, C. A. (2003). Breviarios jurídicos, mediación y conciliación en México: vías alternativas de solución de conflictos a considerar. México, D.F.: Porrúa.

MUNGUÍA, B. M. (1999). Mediación y resolución de conflictos, una guía introductoria. México, D.F.: Paidós.

PÉREZ, J. G. (1995). El derecho a la tutela jurisdiccional. Madrid: Civitas.

SCHIFFRIN, A. (2005). La mediación, aspectos generales. Argentina: Paidós.

\section{Breve currículo:}

\section{Egla Cornelio Landero}

Maestría de Derecho Constitucional, Amparo y Derechos, Humanos; Maestría en Resolución de Conflictos y Mediación, por la Universidad Juárez Autónoma de Tabasco, México; y Master en Gestión y Resolución de Conflictos por la Universidad de Barcelona. Doctoranda del programa de postgrado Doctorado en Métodos de Solución de Conflictos y Derechos Humanos, en la Universidad Juárez Autónoma de Tabasco, México. Miembro del Padrón y Sistema Estatal de Investigadores en el Estado de Tabasco; Académica de Número de la Academia de Derecho del Trabajo y de la Previsión Social en México. Líneas de investigación: Mecanismos de Solución de Conflictos y Derechos Humanos; Conflictos laborales y Seguridad Social. Profesora Investigadora de la Universidad Juárez Autónoma de Tabasco, México. 